\title{
Determination of k-Factors Using the Extrapolation Technique
}

Qiang Jin and Shixin Wang

Micron Technology, Inc., Boise, ID 83707, USA

To overcome the difficulty in foil thickness measurement and other uncertainties in the classical X-ray absorption correction, several extrapolation methods have been proposed [1, 2] to measure the k-factors for quantitative microanalysis. However, they all have their own limitations. In this paper, a more realistic extrapolation technique has been developed and applied to k-factor measurements.

The extrapolation function and the thickness substitute are two important aspects in an extrapolation technique. All possible extrapolation functions originate from the full correction factor (CF) [3], which is frequently used for X-ray absorption correction. The simplified form of correction factor $\mathrm{CF}_{\text {sim }}$ [3] can be obtained under the conditions that all X-rays are generated at the center of the foil. Based on $\mathrm{CF}_{\text {sim }}$, Horita et al. [1] developed the following extrapolation function to determine the absorption-free k-factor $\left(\mathrm{k}_{\mathrm{AB}}\right)_{0}$ :

$$
\log \left(\mathrm{k}_{\mathrm{AB}}\right)=\log \left(\mathrm{k}_{\mathrm{AB}}\right)_{0}+\Delta_{\mathrm{AB}} \cdot \mathrm{t}
$$

where $\mathrm{k}_{\mathrm{AB}}$ is the k-factor measured at a location with thickness $t$, and $\Delta_{A B}$ is a constant for a given take-off angle. However, Eq. (1) is valid only when the thickness of the foil is less than $\mathrm{t}_{1}$, which is defined as the thickness where the deviation between $\mathrm{CF}$ and $\mathrm{CF}_{\text {sim }}$ is about $10 \%$ [3], as shown in Fig. 1. The value of $t_{1}$ mainly depends on the difference in mass absorption coefficients of elements $A$ and $B$ in the sample. When $t_{1}$ is too small, the spectra collected from a typical TEM sample may all come from locations thicker than $\mathrm{t}_{1}$. In this case, an alternative extrapolation function has to be used. In general, a polynomial can be fitted into the CF curve for a given thickness range, and a linear regression $\mathrm{CF}_{\text {fit }}=\mathrm{a}+\mathrm{bt}$ seems sufficient in most cases. Thus, the corresponding extrapolation function for the thickness range between $t_{2}$ and $t_{3}$ (Fig.1) can be express as:

$$
\mathrm{k}_{\mathrm{AB}}=\left(\mathrm{k}_{\mathrm{AB}}\right)_{0} \cdot(\mathrm{a}+\mathrm{bt})
$$

where the values of $a$ and $b$ can be determined by linear regression of the CF curve in this thickness range. The absorption-free $\mathrm{k}$-factor $\left(\mathrm{k}_{\mathrm{AB}}\right)_{0}$ is obtained by the extrapolated k-factor at zero thickness divided by $a$. It should be noted that, even for the extrapolation technique, the absolute foil thickness needs to be estimated in order to use the appropriate extrapolation function, but the accuracy of the thickness is not as crucial as that required for the absorption correction.

To find the thickness substitute, EELS log-ratio method, $t=\lambda_{\mathrm{SP}} \ln \left(\mathrm{I}_{\mathrm{T}} / \mathrm{I}_{0}\right)$ [4], is used, where $\lambda_{\mathrm{SP}}$ is the inelastic mean free path of the sample, $\mathrm{I}_{\mathrm{T}}$ and $\mathrm{I}_{0}$ are intensities of the whole EEL spectrum and the zero-loss peak, respectively. Eqs. (1) and (2) thus become:

$$
\begin{gathered}
\log \left(\mathrm{k}_{\mathrm{AB}}\right)=\log \left(\mathrm{k}_{\mathrm{AB}}\right)_{0}+\Delta_{\mathrm{AB}} \lambda_{\mathrm{SP}} \ln \left(\mathrm{I}_{\mathrm{T}} / \mathrm{I}_{0}\right) \\
\mathrm{k}_{\mathrm{AB}}=\left(\mathrm{k}_{\mathrm{AB}}\right)_{0} \cdot\left[\mathrm{a}+\mathrm{b} \lambda_{\mathrm{SP}} \ln \left(\mathrm{I}_{\mathrm{T}} / \mathrm{I}_{0}\right)\right]
\end{gathered}
$$

$\ln \left(\mathrm{I}_{\mathrm{T}} / \mathrm{I}_{0}\right)$ can be easily obtained with high accuracy in a modern analytical electron microscope. For a given material and EELS collection setup, $\lambda_{\mathrm{SP}}$ is a constant. Therefore, $\ln \left(\mathrm{I}_{\mathrm{T}} / \mathrm{I}_{0}\right)$ can be used 
as the thickness substitute in the extrapolation. The advantages of doing so include (1) replacing the uncertain thickness measurement with the more accurately measured $\ln \left(\mathrm{I}_{\mathrm{T}} / \mathrm{I}_{0}\right)$ in absorption correction; (2) being able to estimate the thickness range easily from the existing formula [4, 5] for the selection of extrapolation function; and (3) being able to apply to any material.

By using the extrapolation technique described above, the k-factors were measured from a number of standard materials. The samples were prepared by grinding the powder materials to submicrometer size followed by dispersion onto holey-carbon films supported by copper TEM grids. The analysis was performed on areas without overlapped carbon film using a JEOL 2010F AEM operated at $200 \mathrm{kV}$. X-ray spectra were collected with an Oxford $\mathrm{Si}(\mathrm{Li})$ detector and analyzed with INCA software. The measured k-factors are compared with theoretical values in Table 1 and plots of $\mathrm{k}_{\mathrm{AB}}$ versus $\ln \left(\mathrm{I}_{\mathrm{T}} / \mathrm{I}_{0}\right)$ are given in Fig. 2 for some materials.

\section{References}

[1] Z. Horita, T. Sano and M. Nemoto, Ultramicroscopy 21 (1987) 271.

[2] E.V. Cappellen, Micros. Microanal. Microstruct. 1 (1990) 1.

[3] A.D. Westwood, J.R. Michael and M.R. Notis, J. Microsc. 167 (1992) 287.

[4] T. Malis, S.C. Cheng, and R.F. Egerton, J. Elec. Microsc. Tech. 8 (1988) 193.

[5] Q. Jin and D. Li, Micros. Microanal. Suppl. 2, 12 (2006).

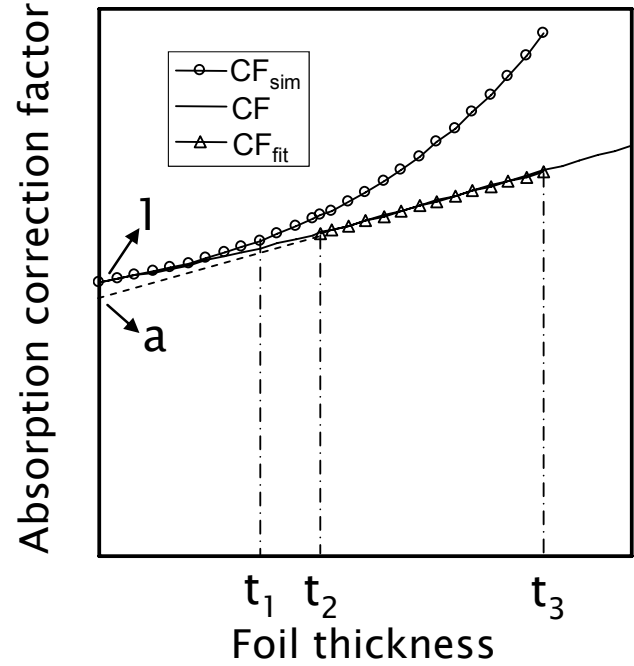

Fig.1 Schematic showing different extrapolation functions suggested for different thickness regimes.

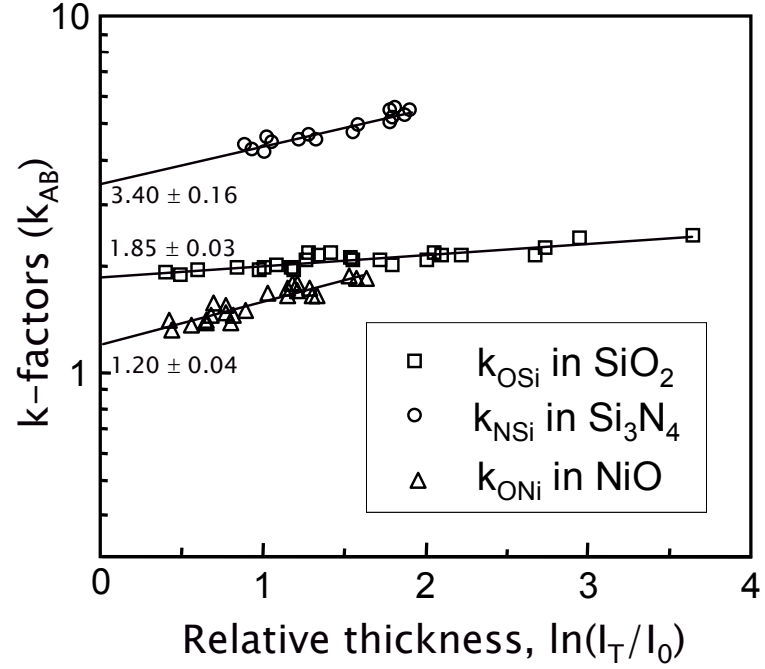

Fig. 2 log-linear plots of the variation of $\mathrm{k}_{\mathrm{AB}}$ with $\ln \left(\mathrm{I}_{\mathrm{T}} / \mathrm{I}_{0}\right)$. Extrapolation to zero thickness results in the absorption-free $\mathrm{k}$-factor $\left(\mathrm{k}_{\mathrm{AB}}\right)_{0}$.

Table 1 Measured k-factors with standard error and their corresponding theoretical values provided in INCA software (total X-ray intensity of a particular line series (e.g. $\mathrm{K}_{\alpha}+\mathrm{K}_{\beta}$ ) used for each element)

\begin{tabular}{lllllllllllll}
\hline Materials & $\mathrm{SiO}_{2}$ & $\mathrm{Al}_{2} \mathrm{O}_{3}$ & $\mathrm{NiO}$ & $\mathrm{CoO}$ & $\mathrm{MnO}$ & $\mathrm{MnO}_{2}$ & $\mathrm{AIN}$ & $\mathrm{Si}_{3} \mathrm{~N}_{4}$ & $\mathrm{TiSi}_{2}$ & $\mathrm{Ti}_{5} \mathrm{Si}_{3}$ & $\mathrm{CoSi}_{2}$ & $\mathrm{WSi}_{2}$ \\
\hline $\mathrm{k}_{\mathrm{AB}}(200 \mathrm{kV})$ & $\mathrm{k}_{\mathrm{OSi}}$ & $\mathrm{k}_{\mathrm{OAI}}$ & $\mathrm{k}_{\mathrm{ONi}}$ & $\mathrm{k}_{\mathrm{OCo}}$ & $\mathrm{k}_{\mathrm{OMn}}$ & $\mathrm{k}_{\mathrm{OMn}}$ & $\mathrm{k}_{\mathrm{NAl}}$ & $\mathrm{k}_{\mathrm{NSi}}$ & $\mathrm{k}_{\mathrm{TiSi}}$ & $\mathrm{k}_{\mathrm{TiSi}}$ & $\mathrm{k}_{\mathrm{CoSi}}$ & $\mathrm{k}_{\mathrm{W}(\mathrm{M}) \mathrm{Si}}$ \\
\hline Measured & 1.85 & 1.69 & 1.2 & 1.18 & 1.21 & 1.19 & 3.18 & 3.4 & 1.12 & 1.08 & 1.55 & 1.71 \\
\hline Std. error $(\sigma)$ & 0.03 & 0.04 & 0.04 & 0.07 & 0.05 & 0.04 & 0.28 & 0.16 & 0.02 & 0.01 & 0.02 & 0.16 \\
\hline Standardless & 1.81 & 1.73 & 1.45 & 1.46 & 1.57 & 1.57 & 2.84 & 2.97 & 1.05 & 1.05 & 1.24 & 1.59 \\
\hline
\end{tabular}

